\title{
EVALUATION OF THERMAL COMFORT IN OPEN GREEN SPACES USING THE ENVI-MET PROGRAM
}

\author{
Fatma AL Zahraa El bdarany, Nanees Abd-Elhamid Elsyad and Ibrahim Rizk Hegazy \\ Mansoura University, Faculty of Engineering, Department of Architecture
}

\begin{abstract}
ABASTRACT
The paper introduces a thermal comfort examination executed in a public garden located in new Damietta city. The aim of this study is to find the optimum land cover and vegetation options of the study area by means of numerical simulations. For this evaluation the modelled micro- and bio-climatological conditions of a typical summer day (15th July 2017) were analyzed. The thermal and radiation environments of the playground were quantified by one of the most popular bio-climatological comfort index Predicted Mean Vote (PMV) and the Mean Radiant Temperature (Tmrt). The simulations of the Achieved parameters were done by the microclimate model ENVI-met. The results were received proved that the modelled area Submitted a variety of thermal conditions for the visitors due to the different land covers. Furthermore this paper confirms the important effect of the vegetation on the human thermal sensation.
\end{abstract}

Key words: Predicted Mean Vote (PMV), Mean Radiant Temperature (Tmrt), thermal comfort, open green space, ENVI-met.

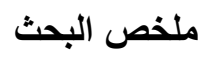

\section{INTRODUCTION}

Green spaces are the lungs of any city it is a population outlet in cities and villages. Egyptian cities are historically characterized by high densities and compacted urban forms, developed through cultural, religious and climatic factor. The sustainability challenge facing such cities is finding new and more appropriate ways of greening high density, compact and diverse urban environments.

ENVI-met is a computer program to simulate the microclimate in urban environment. It is a helpful program to simulate the urban climate in cities and can assist for environmental planning of new towns. In order to achieve outdoor thermal comfort in hot zones it is necessary to have a clear Understanding of the interactions between the prevailing climate and the urban form.

Urban planning in general and within it the planning of urban green spaces is a very complex process and it has several climatological aspects. The final shape of an urban park is 
defined by the aspects of the architecture but this final setup determines the microclimate of that area and finally the thermal comfort of the visitors. As a result of the thermal comfort conditions the visitors or users of the urban park may alter their opinion about it. If the park is perfect from an architectural point of view, but heat stress frequently occurs there, the visitors will avoid the area.

In the last decades there were numerous researches in the topic of microclimate and thermal comfort, therefore now several methods and software are available to predict the microclimate conditions of an urban park when it is only in the planning stage, or before the construction starts,(e.g. Lehme and Bruse 2003, Gulyás et al. 2006, Chow et al. 2011, Fröhlich and Matzarakis 2012). The main aim of this paper is Access to the maximum thermal comfort of users using green. This study is an example for this type of micro-scale modelling, which can give useful information for the architects to make sure that the constructed open space or park has in the end the optimal or best setup in several aspects.

\section{MATERIAL AND METHODS}

\subsection{Explanation of the case study}

The current human thermal comfort tests were conducted in downtown New Damietta It is located in the northeastern part of Egypt, located at (Latitude $+\mathrm{N},-\mathrm{S}, 31.6$ \& longitude $+\mathrm{E}$, $\mathrm{W}, 31.4)$. The large area of about $480 \mathrm{~m} \times 320 \mathrm{~m}=153600 \mathrm{~m} 2$ is one of the most used gardens in the city .In this open door, children can choose from many of the games as well as swings, as a lot of offers for visitors to sit seats. There is also a social building, a mosque and a theater. (Fig. 1).

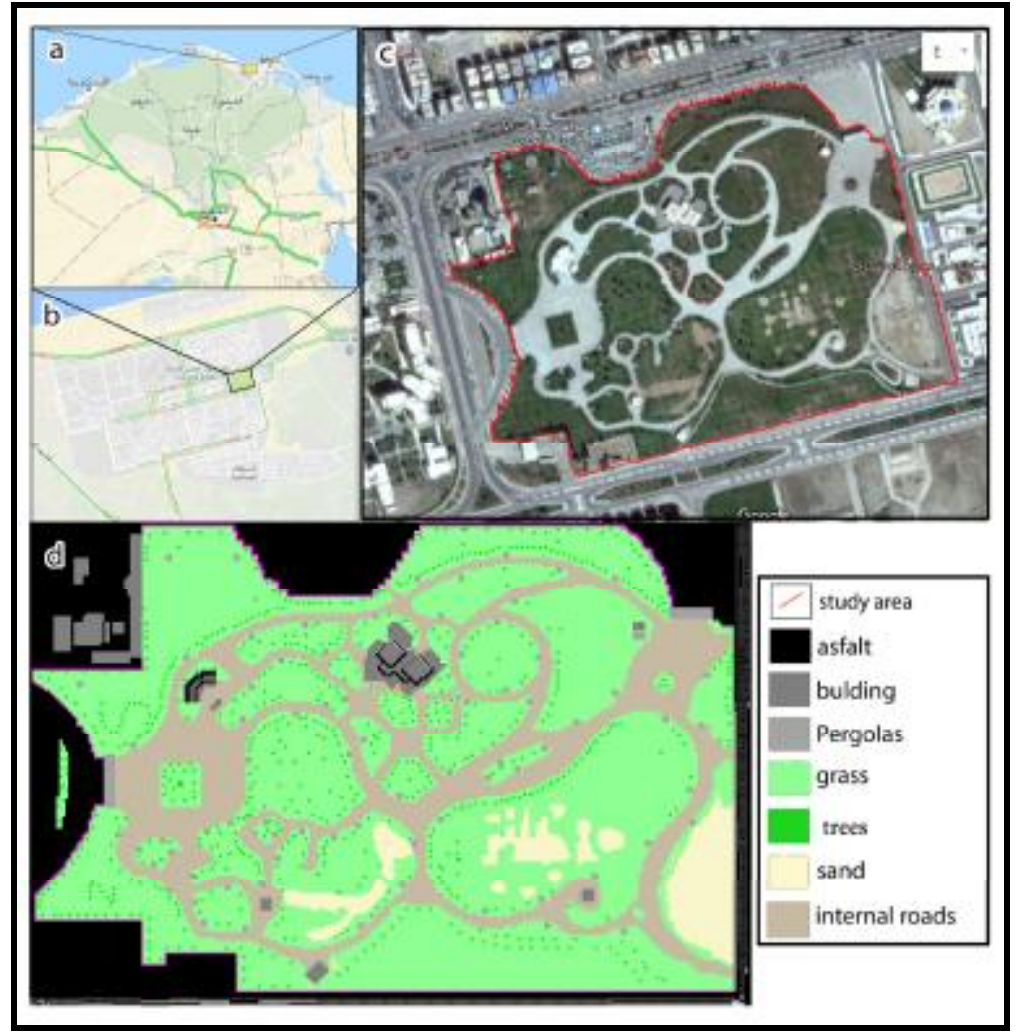

Fig. 1 Geographical location of Egypt (a) and new Damietta city (b);

Detailed maps from google earth of case study (c) and case study from Envi-met (d)

The surface of the area is covered mainly with a green surface of $2-3 \mathrm{~cm}$ height to protect the children from injuries with a large sandy part of the game area in the northeastern part. There is a large amount of vegetation (mostly falling trees) but scattered over the large area. So during the early afternoon and early Afternoon hours A large part of the garden is exposed to sunlight. (Fig. 2) 

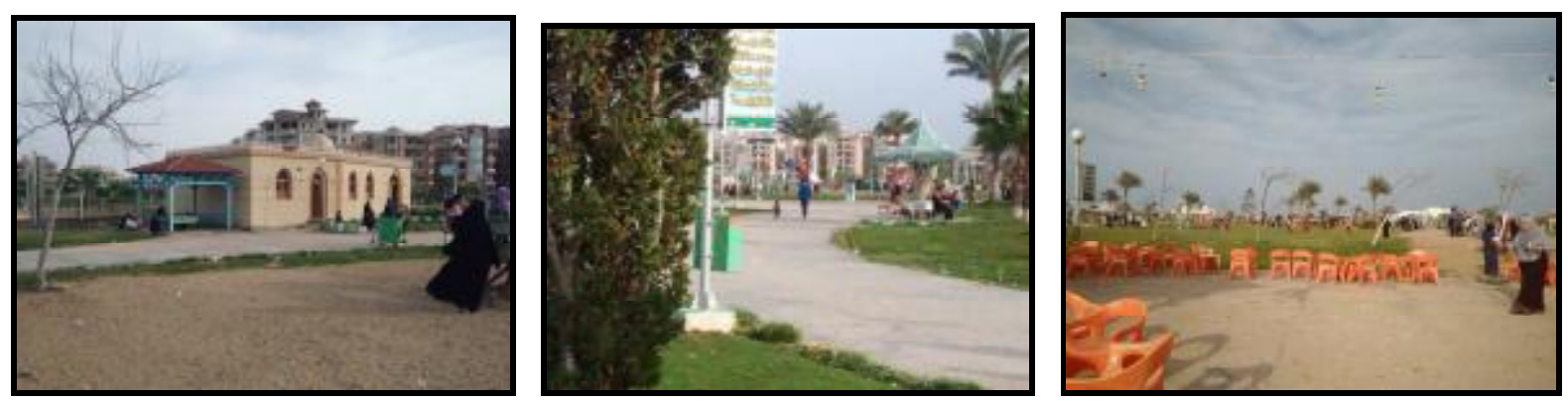

Fig. 2 Photographs of the investigated playground

\subsection{Methods}

This study applies the ENVI-met model to compare the effects of covers and different designs on partial and human comfort conditions. ENVI met is a non-hydrostatic threedimensional climate model capable of modeling interactions in the surface-atmosphere system with relatively high time accuracy (10 minutes) and spatial $(0.5-10 \mathrm{~m})$ (Woller 1998). Simulations require two sets of input data: The configuration file (.cf) contains the basic settings and meteorological parameters required for simulation, while the zone input file (.in) includes morphological elements (buildings, plants, floor coverings, etc.) of the case study.

The microbiological environment of the study area was determined by two thermometers along with air temperature: Mean Radiant Temperature (Tmrt) describes the radiation environment of a region, while Predicted Mean Vote (PMV) determines the thermal sensation of people. Tmrt is defined as the standard temperature of the ocean surface giving black body radiation (emission factor, $\varepsilon=1$ ) which produces the same energy gain for the human body as the prevailing radiation flows (Hopper 1992). The other PMV predicts the average assessment of the thermal environment of a large sample of human beings by values according to the original seven point (from 3 to +3 ) ASHRAE scale. This comfort scale is approximately 0 as comfortable, and higher and lower values indicate an increased likelihood of heat disturbance as well as heat and cold stress, respectively. In (extreme) real weather conditions, PMV can be higher than +3 or less than -3 (Mayer and Hopper 1987, Mayer 1993) (Fig. 3)

\begin{tabular}{|c|c|c|c|c|c|c|c|c|c|}
\hline $\begin{array}{c}\text { THERMAL } \\
\text { SENSATION } \\
\text { PMV }\end{array}$ \\
$\begin{array}{c}\text { very } \\
\text { cold }\end{array}$ & cold & cool & $\begin{array}{c}\text { slightly } \\
\text { cool }\end{array}$ & $\begin{array}{c}\text { neutral } \\
\text { comfortable }\end{array}$ & $\begin{array}{c}\text { slightly } \\
\text { warm }\end{array}$ & warm & hot & $\begin{array}{c}\text { very } \\
\text { hot }\end{array}$ \\
\hline-4 & -3 & -2 & -1 & 0 & 1 & 2 & 3 & 4 \\
\hline $\begin{array}{c}\text { PHYSIOLOGICAL } \\
\text { STRESS LEVEL }\end{array}$
\end{tabular}

Fig. 3 PMV scale for various thermal sensation and stress levels (according to Mayer 1993)

Table 1 the basic input parameters of the simulation

\begin{tabular}{lr}
\hline \multicolumn{2}{c}{ Parameter Input value } \\
\hline Temperature $(\mathrm{K})$ & $\mathbf{3 0 2}$ \\
\hline Relative humidity in $2 \mathrm{~m}(\%)$ & $\mathbf{6 7}$ \\
\hline Wind speed in $10 \mathrm{~m}(\mathrm{~m} / \mathrm{s})$ & $\mathbf{2 . 2}$ \\
\hline Wind direction $\left(^{\circ}\right)$ & $\mathbf{3 0 0}$ \\
\hline $\begin{array}{l}\text { Spec. humidity in } 2500 \mathrm{~m} \\
(\mathrm{~g} / \mathrm{kg})\end{array}$ & $17 . \varepsilon$ \\
\hline Roughness & $\mathbf{0 . 0 1}$ \\
\hline Total simulation time $(\mathrm{h})$ & $\mathbf{6}$ \\
\hline Start simulation & $\mathbf{1 1 : 0 0 ~} \mathbf{~ a m}$ \\
\hline
\end{tabular}



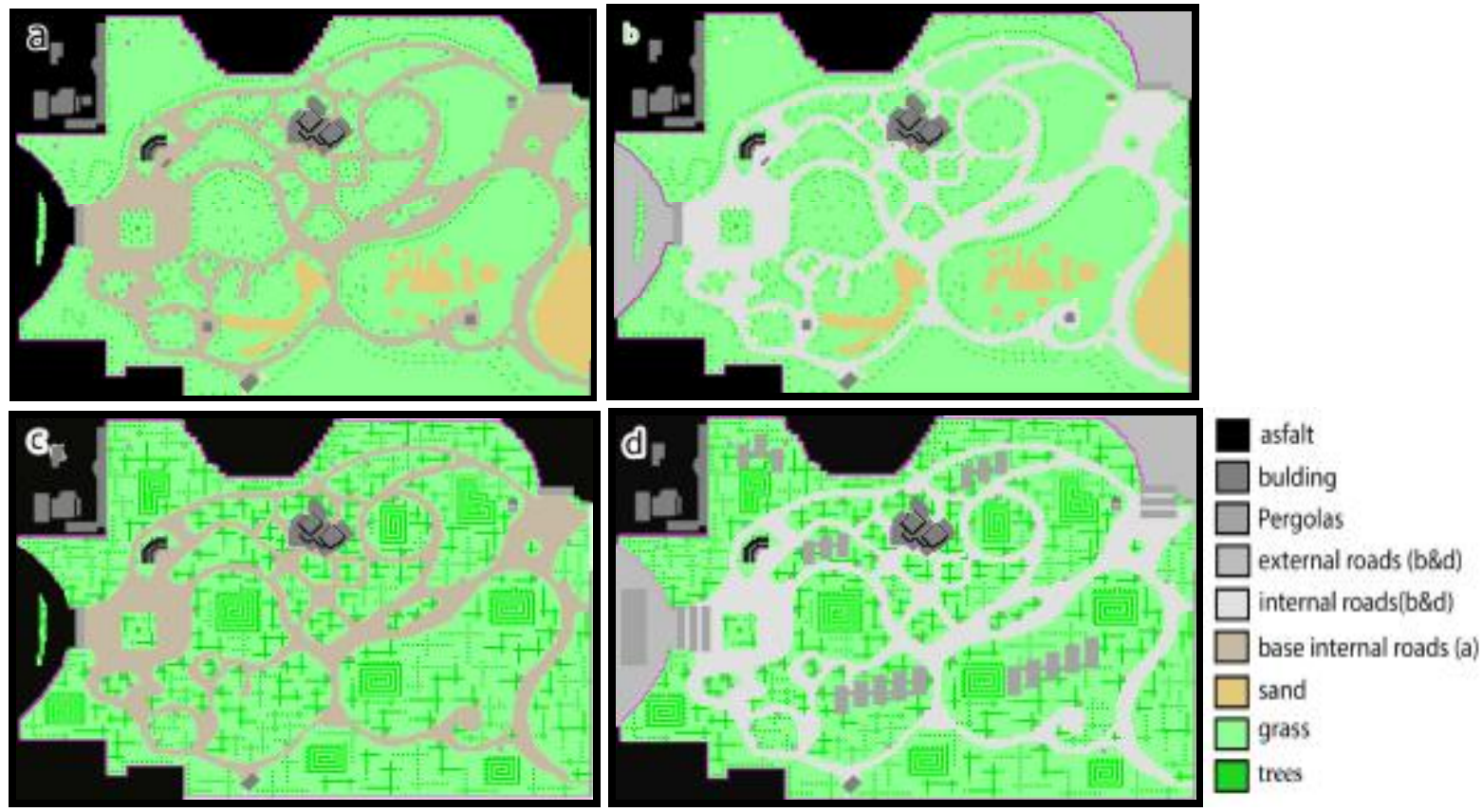

Fig. 4 Graphic images of the four scenarios simulation

The simulation was run on a typical hot, cloudless summer day (15th July 2011), because the differences in the thermal and microclimatic environment can clearly be observed at this time. As parameters of the modelling procedure, 6 hours (from 11 a.m. to 4 p.m.) of total simulation time and a spatial resolution of $1.5 \mathrm{~m}$ were adjusted in ENVI-met. Table 1 shows the basic settings of the simulation and the necessary meteorological data obtained from weather file meteonorm 7 New Damietta.

Four simulation scenarios were created in ENVI-met to find the optimal floor coverings and design for the case study. Scenario 1 contains the base area without any modification (Fig. 4a). The Solar Reflectance Index (SRI) is a measure of the solar reflectance and emissivity of materials that can be used as an indicator of how hot they are likely to become when solar radiation is incident on their surface. The lower the SRI, the hotter a material is likely to become in the sunshine. (SRI) is a measure of the roof's ability to reject solar heat. In Scenario 2 the footpaths were changed to (SRI) $=114$ (Fig. 4b). In the case of scenario 3, the vegetation density was increased, but the original internal pathway type was retained (Figure 4c). Finally, in Scenario 4, all scenarios of changing the type of tiles and increasing trees were combined with the work of pergolas to mislead certain parts of the garden (Figure 4d).

This paper describes the results of these modifications at a specific time (12 am) on the simulation day that was examined, when differences in climatic conditions can be observed more easily.

\section{RESULTS AND DISCUSSION}

\subsection{Thermal and radiation characteristics of the base area without modification.}

In the first part of the analysis, the results of Scenario 1 were examined. Fig. 5 A shows that the spatial patterns of the simulated air temperatures were relatively variable and that the differences are greater than a few degrees Celsius throughout the region. Higher values (about $31.5^{\circ} \mathrm{C}$ ) occurred in the northwest areas on the garden boundary. In the eastern and southern parts, where the vegetation is large, the temperature was slightly less hot $\left(29.7-30.8^{\circ} \mathrm{C}\right)$. 

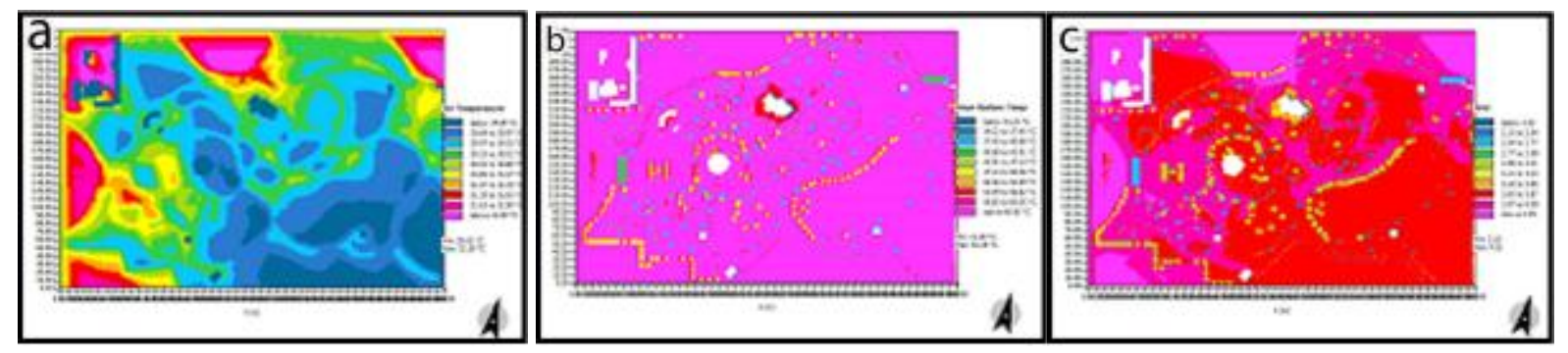

Fig. 5 The thermal features of the planned area without modification (scenario 1)

However, Tmrt and PMV (Figs. 5b and 5c), which represent the spatial distribution of the radiative environment and thermal sensation, were Relatively homogeneous, demonstrating the complexity of these biomarkers compared to air temperatures. At the same time, these maps show the effects of different vegetation types and vegetation on the human thermal sensation. Spatial distributions of Tmrt and PMV values were similar, supporting the fact that the radiation factor plays a very important role in human thermal sensation at this time of year.

To the strong direct radiation of this period as well as the large reflected radiation from the pavement surface, the highest values of tempers $\left(60^{\circ} \mathrm{C}\right)$ occurred throughout the entire park. Under the trees fall thermal values slightly $\left(43^{\circ} \mathrm{C}\right)$.However, significant decreases in values can be found only in shaded areas under pergolas (37- $40^{\circ} \mathrm{C}$ ). Map shows heat stress (PMV map) Most parts of the park are high thermal (4.0-3.6 = PMV), (warm thermal sensation) due to the increased radiation mentioned above. However, under trees and under pergolas where both incoming and reflected radiation flows were small at this time, the thermal conditions were more comfortable and the values were close to PMV $=0$ (neutral thermal sensation) and PMV $=-1$ (slightly cold thermal sensation).

\subsection{The effects of the area modification on the thermal conditions.}

In order to compare scenarios, difference maps were created. In these maps, the model was introduced to the base case values (area without modification, Fig 5) of the corresponding values for the specified scenario (2-4) scenarios, and thus can be observed the effects of modification more easily.

According to Fig 6A, air temperature decreased slightly in Scenario 2 (footpaths were changed to higher Albedo \& Emissivity), which can be explained by the high reflectivity ability not to retain heat. However, this difference exceeded $1.00^{\circ} \mathrm{C}$ in most areas adjacent to the corridors, so the effect of the adjustments in Scenario 2 was significant and should be taken into consideration.
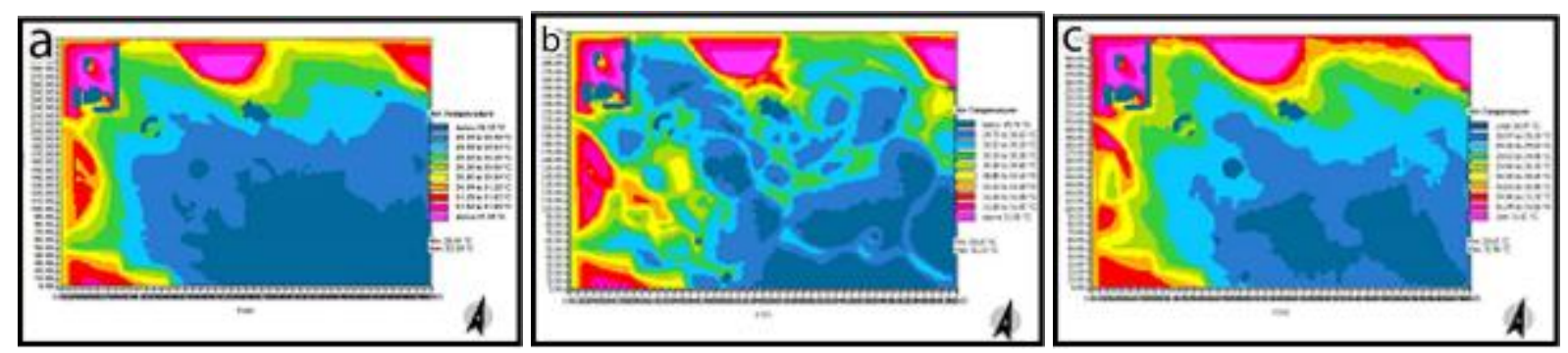

Fig. 6 Difference maps of the modelled air temperature $\left({ }^{\circ} \mathrm{C}\right)$ at different scenarios

The differing heat distribution can be observed in the case of Scenario 3 (simulation with the increase in trees): Although the air temperature is lower in the shade of the trees, the cooling effect of the general site was minimal (Fig. 6B ).

On the map of Scenario 4 (simulation with increasing trees and changing lanes with the work of pergolas), Values varied and differed between 28.6 to $31.6^{\circ} \mathrm{C}$ (Fig. $6 \mathrm{c}$ )

Positive variations، a decrease in air temperature, occur mainly on the south-east side of the study area, where wind direction and velocity is affected. In the northwestern part of the simulation area, a large group of trees was increased. In the middle of the park at the play area, large coverage was done to shade the area (Fig 4D). 
which gave way to the prevailing northwesterly wind (Table 1). The incoming wind cooled down the environment, therefore the temperature in the middle and south part of the area slightly decreased.
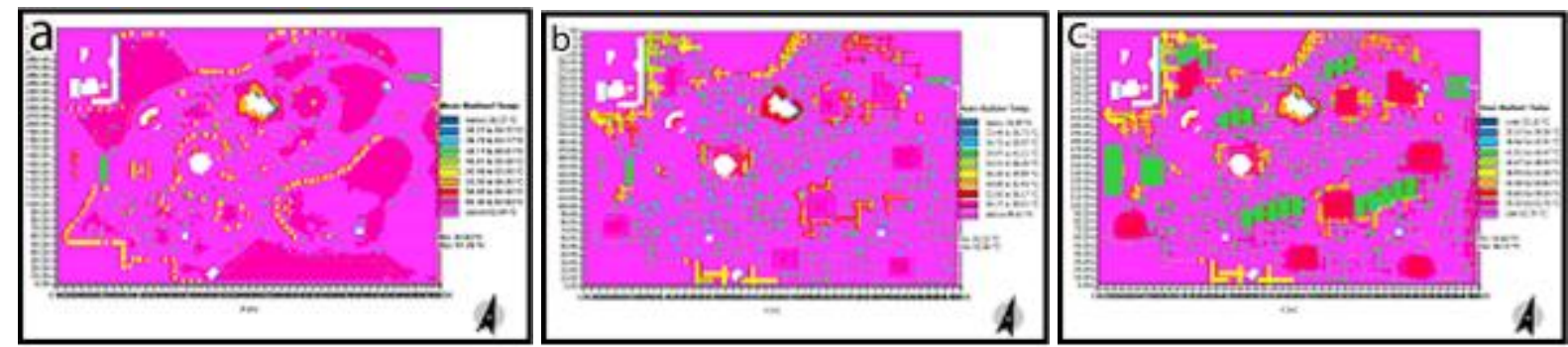

Fig. 7 Difference maps of the modelled $\operatorname{Tmrt}\left({ }^{\circ} \mathrm{C}\right)$ at different scenarios

As shown in Fig 7, the difference in the conditions of thermal radiation was not significant in the first two maps (Scenarios 2 and 3). In the case of Scenario 2, the deviation values for Tmrt values are not realized until $1^{\circ} \mathrm{C}$ (Fig 7a). In scenario 3, the effect of trees was limited on the shaded area to reduce thermal radiation (Fig. 7B). However, Scenario 4 showed that increased vegetation caused significant changes in the radiological environment (Figure 7c). Green spots on the map indicate where trees and pergolas have been placed, where Tmrt values have exceeded $42{ }^{\circ} \mathrm{C}$ due to the resulting shading. Yellow spots also indicate high trees on the edges of the park.
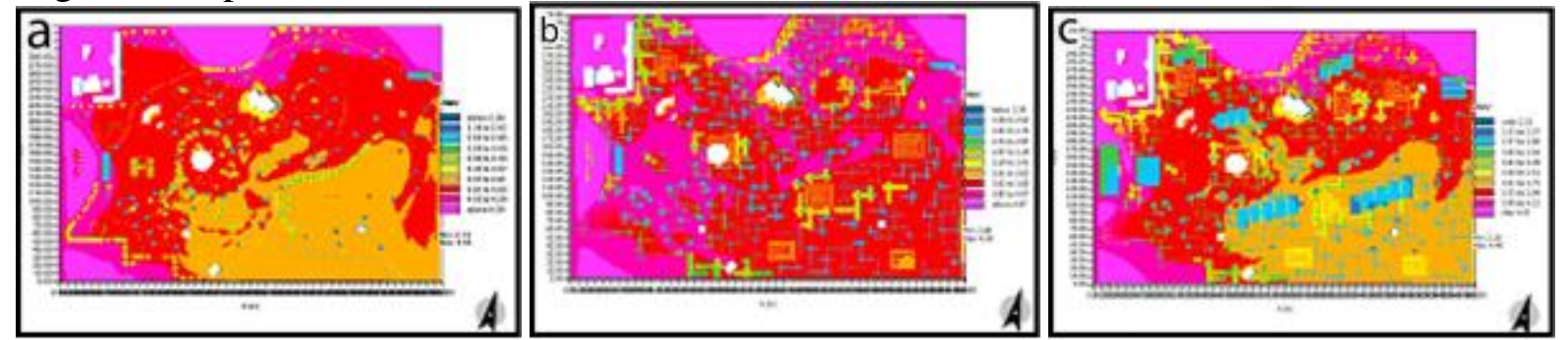

Fig. 8 Difference maps of the modelled PMV at different scenarios

Although the air temperature and Tmrt values are important indicators of thermal comfort, PMV can predict and quantify how people sense the thermal conditions of a given area. Therefore the analysis of the spatial patterns of the PMV values is explicitly pronounced in the investigated scenarios. Fig. 8 shows the difference maps of the modelled PMV values. According to our simulation results, scenarios 2 and 3 caused little changes in the thermal environment (Figs. 8a and 8b). The slight increase of PMV values $(0.1-0.2 \mathrm{PMV})$ in scenario 2 and the reduction of that $(0.0-0 . \vee \mathrm{PMV})$ in the vicinity of the fountain (scenario 3) are almost imperceptible to humans .However, the variation map in scenario 4 highlights the important role of plants in thermal comfort (Figure 8c). Specifically, the increase in trees in certain parts of the park led to a reduction of up to 1.5 PMV, so these areas turned into another category of warmer thermal sensation (slightly warm rather than neutral).In the middle part of the garden, the Less warm PMV values ( $\uparrow . r-\uparrow .8$ ) can be found due to the Northwest wind listed above. Thus, in some cases, the appropriate location of the trees may contribute to the shading and ventilation of the area, thus providing a more comfortable environment in stressful conditions.

\section{CONCLUSIONS}

Some preliminary results of the thermal comfort investigations were presented based on simulation of micro, biological and climatic conditions to discuss the effect of different earth coverings on the sense of thermal comfort. The effects of four simulation scenarios were compared with the ENVI-met simulation, where the thermal environment was characterized by Tmrt and PMV biomarkers as well as air temperature. 
The results of the examination show that the footpaths of a higher (SRI) (Scenario 2) and an increase in trees (Scenario 3) caused slight variations in the thermal state. Contrary to the expected results, the effect of surface adjustments of these two scenarios was not significant according to the maps obtained. This can probably be explained by the fact that it is difficult to treat these minor changes in the model area using the present version of the simulation. However, the outcome of scenario 4 revealed the importance the effect of All methods together (shaded area, Pavement of pedestrian corridors, and vegetation )on the thermal sensation. Increasing the number of trees has led to reduced thermal load in the garden, but at the same time, there was increasing ventilation in the area because of the shaded areas and the prevailing wind.

The aim of this study was to emphasize the importance of the modelling procedure in the process of urban planning and to give a hand in the development of a comfortable urban environment.

\section{REFERENCES}

1. Fröhlich D, Matzarakis A (2012) Modeling of changes in thermal bioclimate: examples based on urban spaces in Freiburg, Germany. Theor Appl Climatol DOI $10.1007 / \mathrm{s} 00704-012-0678$

2. LA ÉGERHÁZI and T GÁL (2012) Assessment of the bioclimatic conditions of a popular play ground by the microclimate model Envi-Met

3. Chow WTL, Pope RL, Martin CA, Brazel AJ (2011) Observing and modeling the nocturnal park cool island of an arid city: horizontal and vertical impacts. Theor Appl Climatol 103:197-211

4. Unger J, Gál T (2011) Automata állomáspár Szegeden - A városi klímamódosító hatás online megjelenítése. [Automatic station pairs in Szeged - The online visualization of the climate modification effect of the city. (in Hungarian)], Légkör 56:93-96

5. Gulyás Á, Unger J, Matzarakis A (2006) Assessment of the microclimatic and human comfort conditions in a complex urban environment: Modelling and measurements. Build Environ 41:1713-1722

6. Lahme E, Bruse M (2003) Microclimatic effects of a small urban park in densely built-up areas: Measurements and model simulations. 5th Int Conf on Urban Climate, Vol 2. University of Lodz, Lodz, Poland. 4

7. Unger J (1999) Comparisons of urban and rural bioclimatological conditions in the case of a Central-European city. Int J Biometeorol 43:139-144

8. Bruse M, Fleer H (1998) Simulating Surface-Plant-Air Interaction Inside Urban Envirenments with a Three Dimensional Numerical Model. Environmental Software and Modelling 13:373-384

9. Mayer H, Höppe P (1987) Thermal comfort of man in different urban environments. Theor Appl Climatol 38:43-49

10. Mayer H (1993) Urban bioclimatology. Experientia 49:957-963

11. Höppe P (1992) Ein neues Verfahren zur Bestimmung der mittleren Strahlungstemperatur in Freien. Wetter und Leben 44:147-151 